\title{
Sex differences among epileptic patients: a comparison of epilepsy and its impacts on demographic features, clinical characteristics, and management patterns in a tertiary care hospital in Egypt
}

\author{
Nirmeen Kishk', Husam Mourad', Sahar Ibrahim², Reham Shamloul ${ }^{1 *}$ D, Aiman Al-Azazi ${ }^{3}$ and Nevin Shalaby ${ }^{1}$
}

\begin{abstract}
Background: Epilepsy is one of the most common neurological conditions. We aimed to identify sex differences in the demographic, clinical features, and treatment strategies in epileptic patients.

Objectives: To analyze and compare the differences in the impact of epilepsy on the socio-demographic characteristics of male and female patients along with gender differences in various types of epilepsies and treatment strategies.
\end{abstract}

Material and methods: A record-based study for 1000 individuals attending the epilepsy outpatient clinic. The medical records were reviewed through a predesigned questionnaire to obtain all relevant data.

Statistical analysis: Data was summarized using range, mean, standard deviation, and median interquartile range for quantitative variable or frequency and percentage for the qualitative ones. Comparison between groups was done using chi-square test.

Results: Females were more illiterate and unemployed compared to males. Tonic-clonic seizures were more frequent in males. Specific epileptic syndromes as juvenile myoclonic epilepsy (JME) were more frequent in females $(p=0.01)$. More males had an underlying secondary etiology $(p=0.001)$. The most common drug used was valproate (51.2\%) which was more utilized by males.

Conclusions: Significant differences between both sexes were observed in certain social impacts in addition to seizure syndromes, etiology, and drug utilization.

Keywords: Epilepsy, Sex differences, Epilepsy impact, Tertiary hospital

\section{Introduction}

Epilepsy was defined in 2005 as a disorder of the brain characterized by an enduring predisposition to generate epileptic seizures and by the neurobiological, cognitive, psychological, and social consequences of this condition [1]. Although the International League Against Epilepsy (ILAE) has developed a new practical (operational) definition of epilepsy [2], still the previous conceptual

\footnotetext{
* Correspondence: reham.shamloul@kasralainy.edu.eg

${ }^{1}$ Neurology Department, Cairo University, Cairo, Egypt

Full list of author information is available at the end of the article
}

definition stands, indicating the importance of the associated consequences in epilepsy disease.

Epidemiologic studies addressing gender differences in epilepsy are surprisingly scarce. Most studies reported that the incidence and prevalence of unprovoked seizures are higher in men than women [3], with some exceptions as juvenile myoclonic epilepsy [4] and absence epilepsy [5] are more common in women. Gender also has an important impact on the epileptic patient regarding health considerations, hormonal changes, and social function [6]. Almost all studies that examined sex 
differences in epilepsy focused on the seizure characteristics without much emphasis on the patients' characteristics.

\section{Patients and methods}

The aim of the current study was to investigate the differences in the demographic and social characteristics between epileptic male and female patients to compare its impact and define gender differences in various types of epilepsies and epileptic syndromes and treatment strategies.

This is a descriptive, record-based, retrospective study of 1000 patients with epilepsy who visited our epilepsy outpatient clinic in the period from January 2012 until January 2015.

The epilepsy clinic receives an average of 25 new epileptic cases and 350 follow-up cases per week.

Data were collected from the epilepsy outpatient clinic data sheets. Records with incomplete, non-conclusive clinical data or proved non-epileptic were excluded. We used Excel to generate a simple random sample of 500 male and 500 female patients. Each sheet provided detailed personal and clinical data, including results of relevant laboratory, neurophysiological and brain imaging, and history of antiepileptic drug (AED) use, responsiveness, and compliance. The sheets were not registered unless the patient him/herself was present with a reliable informant and both were interviewed by an experienced neurology staff member. A structured protocol was used to collect all relevant clinical information for each case.

The data included geographic distribution, gender, age, contact information, education, marital status, and occupation. Occupation was categorized as risky and non-risky according to the presence of a potential risk from the occupation that may expose the patient to danger [7].

We also recorded age at onset, family history, history of febrile convulsions, drug/substance abuse (as tramadol, cannabis, alcohol, clonazepam), and comorbidities. The comorbidities addressed in this study were those related to epilepsy either in terms of etiology or prediction of intractability.

We studied details related to seizure characteristics, underlying etiologies, prodromal symptoms, and precipitating factors, and we recorded neurophysiological and imaging results when available in addition to the types and numbers of antiepileptic drugs used.

Precipitating factors were defined as those circumstances that precede the onset of an epileptic attack and are considered by both the patient and the neurologist to provide a possible explanation as to why the seizure occurred [8], such as sleep deprivation, psychological/ physical/mental stress, flickering lights, fever, use of epileptogenic drugs, and change of generic brand drugs.
Prodromal symptoms: prodromes were operationally defined as signs or symptoms, perceived by the patient and/ or observer as premonitory, appearing up to $24 \mathrm{~h}$ preceding seizure onset, such as headache, pain, paresthesia, sleep/appetite disturbance, genitourinary/gastrointestinal symptoms, fatigue, speech disorders, and cognitive/behavioral or mood changes.

Epilepsy is considered as a condition characterized by recurrent (two or more) epileptic seizures occurring at least $24 \mathrm{~h}$ apart, unprovoked by any immediate identifiable cause [9]. Seizures are classified according to the guidelines of the International League Against Epilepsy (ILAE) [10]. Epilepsy is classified as idiopathic, symptomatic, or cryptogenic [11]. Family history is considered positive when epilepsy is present in a first-, second-, or third-degree relative.

Epilepsy syndrome: A complex of signs and symptoms that define a unique epilepsy condition with different etiologies [12]. The classification of epileptic seizures and syndromes were based on the clinical semiology and electroencephalographic (EEG) findings according to the International League Against Epilepsy's guidelines [13]. The electroencephalograph system used in our unit was a Neuro Galileo NT, PMS, USA machine, its model (Mizar.B8351037899.Version 3.61), unless the patient file stated that it was done elsewhere.

\section{Statistical analysis}

The data was transferred to the statistical package of the social science software program (SPSS Inc., Chicago, IL, USA version 16,2007 ) to be statistically analyzed. Data was summarized using range, mean, standard deviation, and median interquartile range for quantitative variable or frequency and percentage for qualitative ones. Comparison between groups was done using chi-square test.

The study was assessed and approved by the Medical Ethical Committee of Cairo University.

\section{Results}

We analyzed, in depth, 1000 randomly selected data records of 500 male and 500 female patients with epilepsy who visited the epilepsy outpatient clinic, in the period from January 2012 until January 2015.

When comparing patients' demographic and social characteristics, a higher number of male patients were unmarried, had steady jobs, and reported a history of drug abuse (Table 1).

Generalized tonic-clonic seizures were seen more frequently in males while multiple seizure types were detected more in females. We explored the gender differences for patients who were diagnosed with specific epileptic syndromes and found that juvenile myoclonic epilepsy (JME), idiopathic generalized tonic-clonic (IGTC) epilepsy, and 
temporal lobe epilepsy (TLE) were more frequent in females $(p=0.01, p=0.02, p=0.02)$ while juvenile absence epilepsy (JAE) was more common in males $(p=0.02)$ (Table 2).

More female patients reported prodromal and precipitating factors for seizure although diurnal seizures were more common in males $(p=0.001)$.

Seizure frequency was recorded in 662 patients: 302 (45.6\%) showed good seizure control $(<1$ seizure in 6 months) of these, and females showed significantly better seizure control and slightly better compliance than males $(p=0.0001)$ (Table 3).

A higher number of males suffered from symptomatic epilepsy $(p=0.001)$, with trauma and birth injuries being the leading causes while lesions due to immune disorders were more common in females (Table 4).

\section{Diagnostic studies for epilepsy}

Slightly higher than half of the patients who had available EEG report (53.1\%) had abnormal EEGs, most of them $(59.7 \%)$ had focal, rather than generalized (40.2\%) abnormal epileptiform activity. Only $35 \%$ of the patients with available neuroimaging studies had abnormal findings. Neither the EEG nor neuroimaging results revealed significant sex differences, as shown in Table 5.

\section{Antiepileptic drugs (AED) utilization}

Detailed drug history showed that a higher number of males were on monotherapy. Valproic acid (VPA) followed by carbamazepine (CBZ) was the most frequently prescribed AEDs in both groups, but higher number of males utilized VPA while more females utilized CBZ. Phenytoin was the third most common AED in the male group, while levetiracetam was the third in the female group and was significantly more prescribed to females than males. No significant difference was detected between both groups regarding the rest of the AEDs (Table 6).

\section{Discussion}

Sufficient knowledge of gender differences in epilepsy is still lacking, and the consequences of epilepsy on both

Table 1 Demographic data

\begin{tabular}{|c|c|c|c|c|}
\hline Item & Total & Male & Female & $p$ value \\
\hline Age at presentation & $26 \pm 12.41$ & $26.61 \pm 12.750$ & $26.20 \pm 12.064$ & 0.589 \\
\hline Age of fist seizure & $18.17 \pm 12.414$ & $18.56 \pm 13.218$ & $17.78 \pm 11.544$ & 0.101 \\
\hline \multicolumn{5}{|l|}{ Age of seizure onset } \\
\hline$<1$ year & $535(54.9 \%)$ & $262(53.5 \%)$ & $273(56.4 \%)$ & \multirow[t]{3}{*}{0.630} \\
\hline 18-60 years & $432(44.4 \%)$ & $224(45.7 \%)$ & $208(43.0 \%)$ & \\
\hline$>60$ years & $7(0.7 \%)$ & $4(0.8 \%)$ & $3(0.6 \%)$ & \\
\hline \multicolumn{5}{|l|}{ Patient characteristics } \\
\hline Family history & $229(22.9 \%)$ & $114(49.7 \%)$ & $115(50.2 \%)$ & 0.76 \\
\hline Consanguinity & $202(20.2 \%)$ & $96(47.5 \%)$ & $106(52.4 \%)$ & 0.2 \\
\hline \multicolumn{5}{|l|}{ Residency } \\
\hline Lower Egypt & $606(97.3 \%)$ & $300(49.5 \%)$ & 306 (50.4\%) & \multirow[t]{2}{*}{0.51} \\
\hline Upper Egypt & $44(6.7 \%)$ & $24(54.5 \%)$ & $20(45.4 \%)$ & \\
\hline Illiterate & 186 of $637(29.2 \%)$ & 90 of $339(26.5 \%)$ & 96 of 298 (32.2\%) & 0.069 \\
\hline Married/previously married & $452(71.9 \%)$ & $209(46.2 \%)$ & $243(53.7 \%)$ & \multirow[t]{2}{*}{$0.002^{*}$} \\
\hline Unmarried & $176(28.0 \%)$ & $110(62.5 \%)$ & 66 (37.5\%) & \\
\hline Employed & $243(31.4 \%)$ & $229(94.2 \%)$ & $14(5.8 \%)$ & \multirow[t]{2}{*}{$0.00^{*}$} \\
\hline Un Employed & $531(68.6 \%)$ & $187(35.2 \%)$ & $344(64.7 \%)$ & \\
\hline Occupation risk & 69 of $243(28.3 \%)$ & 69 (28.3\%) & 0 & $0.00^{*}$ \\
\hline Drug abuse & $138(13.7 \%)$ & $134(13.4 \%)$ & $4(0.04 \%)$ & \multirow[t]{5}{*}{$0.00^{*}$} \\
\hline Tramadol & 105 (76.08\%) & $101(96.2 \%)$ & 4 (3.8\%) & \\
\hline Cannabis & 26 (18.8\%) & 26 (100\%) & 0 & \\
\hline Alcohol & $2(1.4 \%)$ & 2 (100\%) & 0 & \\
\hline Clonazepam & $5(3.6 \%)$ & $5(100 \%)$ & 0 & \\
\hline Comorbidities & 720 & 358 (49.7\%) & 362 (50.2\%) & 0.83 \\
\hline
\end{tabular}

${ }^{*} p$ value $<0.05$ is considered statistically significant 
Table 2 Clinical data

\begin{tabular}{|c|c|c|c|c|c|}
\hline \multicolumn{2}{|l|}{ Type of seizure } & Total & Male & Female & $p$ value \\
\hline \multicolumn{2}{|l|}{ Type of focal } & $472(47.2 \%)$ & $233(49.3 \%)$ & $239(50.7 \%)$ & 0.76 \\
\hline \multicolumn{2}{|l|}{ Simple focal } & $50(11 \%)$ & $26(52 \%)$ & $24(48)$ & \\
\hline \multicolumn{2}{|l|}{ Complex partial seizures } & $43(9 \%)$ & $19(44.1 \%)$ & $24(55.9 \%)$ & 0.37 \\
\hline \multicolumn{2}{|l|}{ Focal evolving to generalized: } & $379(80 \%)$ & & & \\
\hline \multicolumn{2}{|l|}{ - Simple focal onset } & $303(64 \%)$ & $151(49.8 \%)$ & $152(50.2 \%)$ & 0.94 \\
\hline \multicolumn{2}{|l|}{ - Complex partial onset } & $76(16 \%$ & $37(48.6 \%)$ & $39(51.4 \%)$ & 1.00 \\
\hline \multicolumn{2}{|l|}{ Type of generalized } & 519 (51.9\%) & $265(51 \%)$ & $254(49 \%)$ & \\
\hline \multicolumn{2}{|l|}{ 1. Typical absence } & $19(3.7 \%)$ & $12(63.1 \%)$ & 7 (36.9\%) & 0.2 \\
\hline \multicolumn{2}{|l|}{ 2. Atypical absence } & $1(0.17 \%)$ & $1(100 \%)$ & 0 & \\
\hline \multicolumn{2}{|l|}{ 3. GTCS } & $358(19 \%)$ & $207(57.8 \%)$ & $151(42.1 \%)$ & $0.04^{*}$ \\
\hline \multicolumn{2}{|l|}{ 4. Tonic } & $17(3.3 \%)$ & $8(47 \%)$ & $9(53 \%)$ & 0.75 \\
\hline \multicolumn{2}{|l|}{ 5. Atonic } & $6(1.1 \%)$ & $2(33.3 \%)$ & $4(66.7 \%)$ & 0.44 \\
\hline \multicolumn{2}{|l|}{ 6. Myoclonic jerks } & $8(1.5 \%)$ & $3(37.5 \%)$ & $5(62.5 \%)$ & 0.49 \\
\hline \multicolumn{2}{|l|}{ Multi-seizure type } & $110(21.1 \%)$ & $32(29 \%)$ & $78(71 \%)$ & $0.004^{*}$ \\
\hline \multicolumn{2}{|l|}{ Unclassified } & $9(0.09 \%)$ & $2(22.2 \%)$ & $7(77.8 \%)$ & 0.45 \\
\hline \multirow[t]{7}{*}{ Identified epilepsy syndromes } & JME & 58 & $14(24.1 \%)$ & $44(75.9 \%)$ & $0.01^{*}$ \\
\hline & JAE & 8 & $7(87.5 \%)$ & $1(12.5 \%)$ & $0.02^{*}$ \\
\hline & CAE & 17 & $8(47.5 \%)$ & $9(52.9 \%)$ & 0.99 \\
\hline & IGTC & 23 & $1(1.8 \%)$ & $22(95.6 \%)$ & $0.02^{*}$ \\
\hline & BECTS & 8 & $4(50 \%)$ & $4(50 \%)$ & 1.0 \\
\hline & FLE & 5 & $2(40 \%)$ & $3(60 \%)$ & 0.99 \\
\hline & TLE & 44 & 17 (38.6\%) & 27 (61.4\%) & $0.02^{*}$ \\
\hline
\end{tabular}

JME juvenile myoclonic epilepsy, JAE juvenile absence epilepsy, IGTC idiopathic generalized tonic-clonic epilepsy, CAE childhood absence epilepsy, BECT benign childhood epilepsy with centrotemporal spike, FLE frontal lobe epilepsy, TLE temporal lobe epilepsy

${ }^{*} p$ value $<0.05$ is considered statistically significant

sexes are not adequately approached. To our knowledge, this is the first report exploring sex differences in psychosocial issues, seizure types, etiological features, and utilization patterns of AEDs in people with chronic epilepsy in Cairo, Egypt.
Patients' demographic and social characteristics

The mean age of onset of epilepsy in our cohort was 26 \pm 12.414 ; this was relatively higher than other studies [14] but may be explained by the presence of a specialized pediatric hospital in our vicinity.

Table 3 Gender differences in different seizure characteristics

\begin{tabular}{|c|c|c|c|c|c|}
\hline \multicolumn{2}{|l|}{ Seizure characteristics } & Total & Male & Female & $p$ value \\
\hline \multicolumn{2}{|l|}{ Precipitating factors } & 203 & $85(41.8 \%)$ & $118(58.2 \%)$ & $0.012^{*}$ \\
\hline \multicolumn{2}{|l|}{ Prodrome } & 75 & $11(14.6 \%)$ & $64(85.2 \%)$ & $0.00^{*}$ \\
\hline \multicolumn{2}{|l|}{ Cluster of seizures } & 107 & $53(49.5 \%)$ & $54(49.4 \%)$ & 1.0 \\
\hline \multicolumn{2}{|l|}{ Status epilepticus } & 70 & $32(45.7 \%)$ & $38(54.3 \%)$ & 0.536 \\
\hline \multicolumn{2}{|l|}{ History of Febrile seizure } & 54 & $27(50 \%)$ & $27(50 \%)$ & 1.0 \\
\hline \multirow[t]{4}{*}{ Timing } & Both diurnal and nocturnal & 623 & $301(48.3 \%)$ & $322(51.7 \%)$ & 0.19 \\
\hline & Only diurnal & 233 & $149(64.9 \%)$ & $84(36 / 1 \%)$ & $0.001^{*}$ \\
\hline & Strictly nocturnal seizures & 102 & $45(44.1 \%)$ & 57 (55.9\%) & 0.25 \\
\hline & On awakening & 18 & $5(27.7 \%)$ & $13(72.3 \%)$ & 0.09 \\
\hline \multirow[t]{2}{*}{ Seizure control $n=662$} & Controlled $>6$ month fit free & $302(45.6 \%)$ & $64(21.2 \%)$ & $238(78.8 \%)$ & $0.0001^{*}$ \\
\hline & Uncontrolled & $360(54.3 \%)$ & $177(49.2 \%)$ & $183(50.8 \%)$ & \\
\hline \multicolumn{2}{|c|}{ Compliance detected in 694} & 305 (43.9\%) & $130(42.6 \%)$ & $175(57.4 \%)$ & 0.09 \\
\hline
\end{tabular}

${ }^{*} p$ value $<0.05$ is considered statistically significant 
Table 4 Gender differences epilepsy etiologies

\begin{tabular}{lllll}
\hline Etiology & Total & Males & Females & $p$ value \\
\hline Unknown & 458 & $224(48.9 \%)$ & $234(51.1 \%)$ & 0.52 \\
Idiopathic & 203 & $82(40.4 \%)$ & $121(59.6 \%)$ & $0.01^{*}$ \\
Secondary & 339 & $194(57.2 \%)$ & $145(42.8 \%)$ & $0.00^{*}$ \\
Trauma & 51 & $41(80.3 \%)$ & $10(19.7 \%)$ & $0.0001^{*}$ \\
Infection & 45 & $17(37.7 \%)$ & $28(62.3 \%)$ & 0.105 \\
Birth injury & 28 & $21(75 \%)$ & $7(25 \%)$ & $0.027^{*}$ \\
Vascular & 21 & $15(71.4 \%)$ & $6(28.6 \%)$ & 0.119 \\
SOL & 16 & $10(62.5 \%)$ & $6(37.5 \%)$ & 0.45 \\
TS & 9 & $4(44.4 \%)$ & $5(55.6 \%)$ & 0.741 \\
Immune disorder & 9 & 0 & $9(100 \%)$ & $0.001^{*}$ \\
MS & 8 & $5(62.5 \%)$ & $3(37.5 \%)$ & 0.725 \\
\hline
\end{tabular}

SOL space occupying lesion, TS tuberous sclerosis, MS mesial sclerosis

${ }^{*} p$ value $<0.05$ is considered statistically significant

Both illiteracy (29.2\%) and unemployment (males $35.2 \%$, females $64.71 \%$ ) were higher in our cohort compared to the general population (illiteracy 20.9\%; unemployment $9.4 \%$ in males and $24.2 \%$ in females) as reported by the Central Agency for Public Mobilization and Statistics (CAPMAS) of Egypt in 2015 [15]. When comparing both sexes, females were more illiterate and significantly higher numbers were unemployed.

Hazardous risks at workplaces were reported only by males $\left(p^{<} 0.00\right)$ and included handling sharp objects or heavy machines, long-hour drivers, builders, and exposure to fire as bakers.

Our study showed that less epileptic patients had ever been married ( $66.1 \%$ male and $80.4 \%$ females) in comparison to the general statistics ( $80 \%$ male and $90 \%$ females) [16], with more single epileptic males than females.

This significant psychosocial impact and the diverse effect of epilepsy on both sexes was also reported by others [17] and may be related, in general, to the epilepsy stigma, in addition to the males' higher social responsibilities [18] and the females' sociocultural restrictions.

The rate of drug abuse in our cohort (13.8\%) was higher than that found in a recent cross-sectional, community-based survey on almost all Egyptian governments [19], which reported that about 6.7\% of the Egyptians were dealing regularly with substance(s). In concordance with our results, they found significantly

Table 5 Gender differences in diagnostic studies

\begin{tabular}{lllll}
\hline EEG recorded in 578 & Total & Male & Female & $p$ value \\
\hline Normal EEG & 307 & $146(47.5 \%)$ & $161(52.4 \%)$ & 0.94 \\
Focal discharge & 162 & $79(48.7 \%)$ & $83(51.2 \%)$ & \\
Generalized discharge & 109 & $51(46.7 \%)$ & $58(53.2 \%)$ &
\end{tabular}

Brain imaging recorded in 377

Abnormal findings $131 \quad 73(55.7 \%) \quad 58(49.2 \%) \quad 0.33$

Table 6 Gender differences in AED utilization

\begin{tabular}{lllll}
\hline AEDs & Total & Male & Female & $p$ value \\
Monotherapy & 593 & $329(55.4 \%)$ & $264(44.6 \%)$ & 0.00 \\
Polytherapy & 338 & $146(43.1 \%)$ & $192(56.9 \%)$ & \\
\hline Distribution of drug prescribed & & & \\
Valproate & 514 & $285(55.4 \%)$ & $229(44.6 \%)$ & $0.0005^{*}$ \\
Carbamazepine & 395 & $187(47.3 \%)$ & $208(52.7 \%)$ & $0.001^{*}$ \\
Levetiracetam & 185 & $62(33.5 \%)$ & $123(66.5 \%)$ & $0.001^{*}$ \\
Phenytoin & 129 & $72(55.8 \%)$ & $57(44.2 \%)$ & 0.186 \\
Lamotrigine & 68 & $33(48.5 \%)$ & $35(51.5 \%)$ & 0.89 \\
Clonazepam & 21 & $11(52.3 \%)$ & $10(47.6 \%)$ & 1.00 \\
Oxcarpazepine & 13 & $8(61.5 \%)$ & $5(38.4 \%)$ & 0.57 \\
Topiramaye & 11 & $3(27.3 \%)$ & $8(72.7 \%)$ & 0.22 \\
Locozamide & 6 & $4(66.7 \%)$ & $2(33.3 \%)$ & 0.68 \\
Ethusoxamide & 6 & $3(50 \%)$ & $3(50 \%)$ & 1.00 \\
\hline${ }^{*} p$ value $<0.05$ is considered statistically significant &
\end{tabular}

higher numbers of male abusers $(15.8 \%$ males versus $2.2 \%$ females). Similarly, Najafi and his colleagues [20], found drug abuse to be more frequent in epileptic patients compared to the general population, with the most frequent substance abused being tramadol.

\section{Seizure types and epilepsy classification}

The relative dominance of generalized epilepsies as seizure type is evident in several Egyptian [21], Arabian [22], and developing countries' studies [23]. However, some epidemiological Egyptian [24] [25] and developed countries' studies [26] reported the predominance of focal seizures. It is expected that in developing countries, in which more symptomatic epilepsy is found, a higher rate of focal seizures should be reported. However, in hospital-based studies, there is greater under-representation of focal epilepsy because of less frequent access for such patients to the hospital due to the less frightening aspect of these seizures, inferring a methodological rather than any real geographic difference.

Our results showed that more females complained of more than one seizure type and the same results were shown by Mullins and his colleagues [27]; however, they reported multi-seizure $(>2)$ type to be equal in both sexes, an observation that we recommend to be further studied. They also found that idiopathic generalized epilepsy (IGE) is more common in females; in our cohort, this was true for JME, IGTC, and TLE, but juvenile absence epilepsy (JAE) was more common in males $(p=0.02)$. However, due to the few numbers of subjects in this group, we suggest that our results would be interpreted with caution.

\section{Seizures pattern and control}

The overall reporting of precipitating factors was 20.3\%; this is less than what was mentioned in previous studies 
[8]. We relate such differences to methodological issues as most of those studies used predesigned, close-ended questionnaires while we recorded what was mentioned in the patients' files during their clinic interviews.

The higher reporting of precipitating factors by our female patients may be related to their having an additional factor related to hormonal changes during menstruation causing changes in seizure frequency in association with menstrual cycles [28]. It is also plausible that differences in both brain-derived and systemically derived estrogens between sexes may lead to differences in responses to the inciting event of the seizure [29].

Similarly, Maiwald and colleagues [30], also found that, out of 500 patients with epilepsy, 31 (6\%) claimed to sense prodromal symptoms and most participants were females.

While differences in symptom reporting based upon sex are due to psychological, biological, or sociological factors remain unclear, the impact of one or all of these factors on epilepsy is points requiring further study [29].

Analysis of seizure timing revealed that males suffered from more diurnal seizures. In the context that males had a significantly higher number of GTCs, we find our results close to Fernández and his colleagues [31], who stated that evolution of GTCs peaks at 6-9 am; however, another study [32] found that tonic-clonic seizure distribution showed no difference between day and night. This disagreement can be related to methodological issues as we depended on self-reporting, while studies evaluating the relationship of sleep/awake and circadian patterns to seizures depended chiefly on EEG analysis [31, 32].

The control of seizures was much better in the female group; this may be attributed to better compliance to medication, idiopathic seizures, stability of social life, and lower rate of substance abuse compared to males. Similar results were reported by Obiako and his colleagues [33] when they investigated prognostic factors for epileptic seizure outcomes.

It is worth noting that the overall percentage of controlled patients $(45.6 \%)$ was inferior to previous studies [34]. This may be related to being a hospital-based study carried out in the tertiary referral hospital, which is usually challenged with more cases of refractory epilepsy while easy-to-treat cases normally achieve good control after the first AED and do not require the assistance of an expert epileptologist; however, we do recommend further studies to investigate this issue.

\section{Etiological causes of symptomatic epilepsy}

A significantly higher number of females had idiopathic etiology, whereas more males had an underlying secondary etiology with trauma being the leading cause. Our results agree with previous reports indicating that head injuries [14] are the most common underlying etiological cause of chronic epilepsy, with males being at a greater exposure risk. When comparing our results with another Egyptian study, led by Farghaly and his colleagues [35], they found that cerebrovascular stroke, rather than trauma, was the most common cause of symptomatic epilepsy among adults and the elderly while perinatal insults were the most common among children $(<18$ years). This difference regarding adult epileptic patients may be related to the geographic characteristics as the mentioned study was carried out in Al-kharga District (New Valley), at the southern part of Egypt, where the majority live in rural areas with a density of $0.58 / \mathrm{km}^{2}$, while the majority of our subjects came from Giza, the third-largest city in Egypt and the world's seventh largest suburb, with a density of $2.300 / \mathrm{km}^{2}$, and the highest number of traffic accidents as reported by The Central Agency for Public Mobilization and Statistics [15].

It is noteworthy that the number of patients with unknown etiology (cryptogenic) is relatively high compared to previous studies $[19,33]$, in addition to low numbers of hippocampal sclerosis and cortical dysplasias detected in our study. This could be due to the limited access to 3Tesla Magnetic Resonance Imaging (MRI) and comprehensive epilepsy protocol imaging for economic reasons.

\section{Diagnostic studies for epilepsy}

Neither the EEG nor neuroimaging results showed gender differences between our cohorts. Although the percentage of patients who had undergone diagnostic tests is comparable to previous studies [14, 16, 17], it is still inadequate for such essential investigations. We attributed this deficiency to the lack of registration in the archived record and/or the reluctance in doing EEG studies either due to financial issues or good control of seizures with treatment.

\section{AED utilization}

Prescribers in our tertiary referral center generally followed treatment guidelines for epilepsy in terms of first-line drugs, with a tendency to shift towards the use of newer AEDs if indicated. Results showed that most patients were treated with first-generation AEDs, which are offered freely. Males were more likely to be prescribed VPA for generalized seizures, with a trend to shift to levetiracetam for females due to its better safety profile on females in the child-bearing period and in hepatic patients.

Since this study included patients attending a tertiary care hospital, it may bear certain selection biases. It did not include patients treated in other neurology clinics, at primary or secondary care centers, those treated privately, or undiagnosed patients. Also, being a retrospective study, some information was liable to recall bias and incompleteness as results of EEG or neuroimaging hindered the recognition of certain features and the diagnosis of epilepsy syndromes in some patients. 


\section{Conclusion}

While epidemiological studies did not find persistent differences in the incidence of epilepsy in males and females, our study revealed significant differences in the psychosocial impact of epilepsy on both sexes in certain areas, such as education, marriage, and hazardous job exposure. Our results go with previous publications that reported that non-symptomatic epilepsy occurs more in women while symptomatic, localization-related epilepsy has a preponderance in men, with different treatment choices by epileptologists in relation to sex.

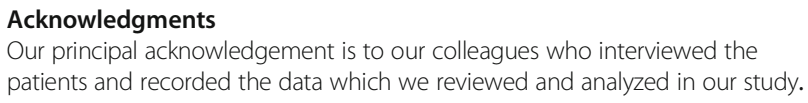

\section{Funding}

There is no source of funding for this research.

\section{Availability of data and materials}

All datasets generated and analyzed during the current study are not publicly available but are available by reasonable request from the corresponding author

\section{Authors' contributions}

All authors contributed to the research idea. NAK, NMS, and AAA contributed to the data collection. NAK and NMS analyzed the data and along with HSM and RMS, interpreted the data. Further, HSM and RMS completed the first draft of the article. All authors were involved in drafting the article or revising it critically for important intellectual content, and all authors approved the final version to be published.

\section{Ethics approval and consent to participate}

All procedures performed in the study were in accordance with the ethical standards of the institutional research committee and with the 1964 Helsinki declaration and its later amendments. The study was ethically approved by the research committee and reviewed by the faculty of medicine Cairo University board on 18 Nov. 2013. Written informed consent was obtained from all participants involved in this investigation prior to the conduct of any study-related activities

\section{Consent for publication}

Not applicable

\section{Competing interests}

The authors declare that they have no competing interests.

\section{Publisher's Note}

Springer Nature remains neutral with regard to jurisdictional claims in published maps and institutional affiliations.

\section{Author details}

${ }^{1}$ Neurology Department, Cairo University, Cairo, Egypt. ${ }^{2}$ Department of Community Medicine, Cairo University, Cairo, Egypt. ${ }^{3}$ Cairo University, Cairo, Egypt.

Received: 5 January 2019 Accepted: 22 April 2019

Published online: 07 June 2019

\section{References}

1. Fisher RS, Van Emde Boas W, Blume W, Elger C, Genton P, Lee P, et al. Epileptic seizures and epilepsy: definitions proposed by the Internationa League Against Epilepsy (ILAE) and the International Bureau for Epilepsy (IBE). Epilepsia. 2005;46:470-2. https://doi.org/10.1111/j.0013-9580.2005. 66104.x.
2. Fisher RS, Acevedo C, Arzimanoglou A, Bogacz A, Cross JH, Elger CE, et al. A practical clinical definition of epilepsy. Epilepsia. 2014;55:475-82. https://doi. org/10.1111/epi.12550

3. Hauser WA, Annegers JF, Kurland LT. Incidence of epilepsy and unprovoked seizures in Rochester, Minnesota: 1935-1984. Epilepsia. 1993;34:453-8. https://doi.org/10.1111/j.1528-1157.1993.tb02586.x.

4. Kotsopoulos IAW, Van Merode T, Kessels FGH, De Krom MCTFM, Knottnerus JA. Systematic review and meta-analysis of incidence studies of epilepsy and unprovoked seizures. Epilepsia. 2002;43:1402-9. https://doi.org/10.1046/ j.1528-1157.2002.t01-1-26901.x.

5. Waaler PE, Blom BH, Skeidsvoll H, Mykletun A. Prevalence, classification, and severity of epilep... [Epilepsia. 2000] - PubMed result. Epilepsia. 2000:41:802-10.

6. Luef $G$, Taubøll E. Gender issues in epilepsy - difference in management of epilepsy. Seizure. 2015;28:1-2. https://doi.org/10.1016/j.seizure.2015.02.001

7. Li X, Sundquist J, Sundquist K. Socioeconomic and occupational risk factors for rheumatoid arthritis: a nationwide study based on hospitalizations in Sweden. J Rheumatol. 2008:35:986-91.

8. Nakken KO, Solaas MH, Kjeldsen MJ, Friis ML, Pellock JM, Corey LA. Which seizure-precipitating factors do patients with epilepsy most frequently report? Epilepsy Behav. 2005;6:85-9. https://doi.org/10.1016/j. yebeh.2004.11.003.

9. Guidelines for epidemiologic studies on epilepsy: commission on epidemiology and prognosis, International League Against Epilepsy. Epilepsia 1993;34:592-596. doi:https://doi.org/10.1111/j.1528-1157.1993. tb00433.x.

10. Proposal for revised clinical and electroencephalographic classification of epileptic seizures: from the commission on classification and terminology of the International League Against Epilepsy. Epilepsia 1981;22:489-501. doi: https://doi.org/10.1111/j.1528-1157.1981.tb06159.x.

11. Brodie MJ, Elder AT, Kwan P. Epilepsy in later life. Lancet Neurol. 2009;8: 1019-30. https://doi.org/10.1016/S1474-4422(09)70240-6.

12. Engel J. Report of the ILAE classification core group. Epilepsia. 2006;47:155868. https://doi.org/10.1111/j.1528-1167.2006.00215.x.

13. Proposal for revised classification of epilepsies and epileptic syndromes: commission on classification and terminology of the International League Against Epilepsy. Epilepsia 1989;30:389-99. doi:https://doi.org/10.1111/j. 1528-1157.1989.tb05316.x.

14. Ge Y, Yu P, Ding D, Wang P, Shi Y, Zhao T, et al. Etiologic features and utilization of antiepileptic drugs in people with chronic epilepsy in China: report from the epilepsy cohort of Huashan hospital $(\mathrm{ECOH})$. Epilepsy Res. 2015;116:99-104. https://doi.org/10.1016/j.eplepsyres.2015.07.006.

15. Central Agency for Public Mobilization and Statistics (CAPMAS) of Egypt in 2015. http://www.capmas.gov.eg/HomePage.aspx\#

16. Rania Salem. Changes in the institution of marriage in Egypt from 1998 to 2012. Working paper 911 May 2015 first published in 2015 by The Economic Research Forum (ERF) Available from: https://erf.org.eg/wp-content/uploads/ 2015/12/911.

17. Ettore B, Massimiliano B. Gender difference in epidemiology and comorbidities of epilepsy. Epilepsy in Women, 2013, p. 1-10. doi:https://doi. org/10.1002/9781118531037.ch1.

18. Munyoki G, Edwards T, White S, Kwasa T, Chengo E, Kokwaro G, et al. Clinical and neurophysiologic features of active convulsive epilepsy in rural Kenya: a population-based study. Epilepsia. 2010;51:2370-6. https://doi.org/ 10.1111/j.1528-1167.2010.02653.x

19. Hamdi E, Sabry N, Sedrak A, Khowailed A, Loza N, Rabie M, et al. Sociodemographic indicators for substance use and abuse in Egypt. J Addict Prev. 2016;4:1-8. https://doi.org/10.13188/2330-2178.1000026.

20. Najafi MR, Sonbolestan SA, Sonbolestan F n.d. The Prevalence of Substance Abuse Among the Epileptic Patients of Isfahan. Shiraz E-Med J. 2011;12(3): 140-3. Online ahead of Print. http://emedicalj.com/en/articles/76435.html.

21. Al-Kattan M, Afifi L, Shamloul R, Mostafa EED. Assessment of precipitating factors of breakthrough seizures in epileptic patients. Egypt J Neurol Psychiatry Neurosurg. 2015;52:165-71. https://doi.org/10.4103/1110-1083. 162002

22. Benamer HTS, Grosset DG. A systematic review of the epidemiology of epilepsy in Arab countries. Epilepsia. 2009;50:2301-4. https://doi.org/10. 1111/j.1528-1167.2009.02058.x.

23. Preux PM, Druet-Cabanac M. Epidemiology and aetiology of epilepsy in sub-Saharan Africa. Lancet Neurol. 2005:4:21-31. https://doi.org/10.1016/ S1474-4422(04)00963-9. 
24. Hashem S, Al-Kattan M, Ibrahim SY, Shalaby NM, Shamloul RM, Farrag M Epilepsy prevalence in Al-Manial Island, Egypt. A door-to-door survey. Epilepsy Res. 2015;117. https://doi.org/10.1016/j.eplepsyres.2015.08.003.

25. El-Tallawy H, Farghaly W, Metwally N, Rageh T, Shehata GA, Badry R, et al. Prevalence of neurological disorders in Al Quseir, Egypt: methodological aspects. Neuropsychiatr Dis Treat. 2013;9:1295-300. https://doi.org/10.2147/ NDT.S42392.

26. Guekht A, Hauser WA, Milchakova L, Churillin Y, Shpak A, Gusev E. The epidemiology of epilepsy in the Russian Federation. Epilepsy Res. 2010;92: 209-18. https://doi.org/10.1016/j.eplepsyres.2010.09.011.

27. Mullins GM, O'Sullivan SS, Neligan A, McCarthy A, McNamara B, Galvin RJ, et al. A study of idiopathic generalised epilepsy in an Irish population. Seizure. 2007;16:204-10. https://doi.org/10.1016/j.seizure.2006.12.007.

28. Herzog AG, Klein P, Ransil BJ. Three patterns of catamenial epilepsy. Epilepsia. 1997;38:1082-8. https://doi.org/10.1111/j.1528-1157.1997.tb01197.x

29. Carlson C, Dugan P, Kirsch HE, Friedman D. Sex differences in seizure types and symptoms. Epilepsy Behav. 2014;41:103-8. https://doi.org/10.1016/j. yebeh.2014.09.051.

30. Maiwald T, Blumberg J, Timmer J, Schulze-Bonhage A. Are prodromes preictal events? A prospective PDA-based study. Epilepsy Behav. 2011;21: 184-8. https://doi.org/10.1016/j.yebeh.2011.02.004.

31. Sánchez Fernández I, Ramgopal S, Powell C, Gregas M, Zarowski M, Shah A, et al. Clinical evolution of seizures: distribution across time of day and sleep/wakefulness cycle. J Neurol. 2013;260:549-57. https://doi.org/10.1007/ s00415-012-6675-3.

32. Zarowski M, Loddenkemper T, Vendrame M, Alexopoulos AV, Wyllie $\mathrm{E}$, Kothare SV. Circadian distribution and sleep/wake patterns of generalized seizures in children. Epilepsia. 2011;52:1076-83. https://doi.org/10.1111/j. 1528-1167.2011.03023.x.

33. Obiako OR, Sheikh TL, Kehinde JA, Iwuozo EU, Ekele N, Elonu CC, et al. Factors affecting epilepsy treatment outcomes in Nigeria. Acta Neurol Scand. 2014;130:360-7. https://doi.org/10.1111/ane.12275.

34. Garcia-Martin G, Perez-Errazquin F, Isabel Chamorro-Muñoz M, RomeroAcebal M, Martin-Reyes G, Dawid-Milner MS. Prevalence and clinical characteristics of epilepsy in the south of Spain. Epilepsy Res. 2012;102:1008. https://doi.org/10.1016/j.eplepsyres.2012.05.008.

35. Farghaly WMA, El-Tallawy HN, Rageh TA, Mohamed EM, Metwally NA, Shehata GA, et al. Epidemiology of uncontrolled epilepsy in the Al-Kharga District, New Valley, Egypt. Seizure. 2013;22:611-6. https://doi.org/10.1016/j. seizure.2013.04.010.

\section{Submit your manuscript to a SpringerOpen ${ }^{\circ}$ journal and benefit from:}

- Convenient online submission

- Rigorous peer review

- Open access: articles freely available online

- High visibility within the field

- Retaining the copyright to your article

Submit your next manuscript at $\boldsymbol{\nabla}$ springeropen.com 